\title{
Innovation in Initial Teacher Education through a School-University Partnership
}

\author{
Kirsty Young ${ }^{1, *}$ \\ ${ }^{1}$ Faculty of Arts and Social Sciences, University of Technology Sydney, Sydney, Australia \\ *Correspondence: Faculty of Arts and Social Sciences, University of Technology Sydney, Sydney, Australia. E-mail: \\ kirsty.young@uts.edu.au
}

Received: November 12, 2019

Accepted: December 19, 2019 Online Published: February 6, 2020

doi:10.5430/jct.v9n1p15

URL: https://doi.org/10.5430/jct.v9n1p15

\begin{abstract}
Global criticism on the quality of initial teacher education has led to calls for reform. One initiative that emerged in Australia was the establishment of Hub School partnerships, which facilitate collaborations between schools and universities to explore how initial teacher education could be improved. This paper reports one such partnership, which applied improvement science in its design to develop an ambitious approach to initial teacher education. A qualitative research approach aimed to uncover the outcomes of the project. The findings from the first prototype are reported herein and highlight the value in cross-faculty mentoring and in providing pre-service teachers opportunities for reflection while immersed in school settings.
\end{abstract}

Keywords: initial teacher education, school-university partnerships, improvement science, evaluation research

\section{Introduction}

Governments across the globe including the United States, United Kingdom (UK) and Australia perceive a crisis in education, evidenced through international summits focused on the problems facing the teaching profession. According to the literature, 'across the world, the teaching profession is at critical stages of reform - both in developed and developing countries' (McMahon, Forde \& Dickson, 2015). In Australia (where this research was conducted), factors feeding into this perceived crisis, including falling student performance as measured on international scales such as the Programme for International Student Assessment and stagnation of results on national scales such as the National Assessment Program - Literacy and Numeracy (NAPLAN). In Australia, the latter is a series of standardised tests conducted in primary schools (Years 3 and 5) and secondary schools (Years 7 and 9) nationwide. These results occurred when efforts made by the government to improve both literacy and numeracy levels increased across the country.

The high attrition rates of teachers in the first five years of their career were also identified as problematic (Buchanan, 2012; Ingersoll \& Smith, 2003). Throughout the 1990s and early 2000s, further evidence emerged that demonstrated such issues as class sizes and government spending had little effect on the success of students, but rather the quality of the teacher had the greatest influence on student performance (Australian Council for Educational Research [ACER], 2014; Dinham, 2015). The identification of a perceived crisis subsequently led to calls for educational reform, which included development in initial teacher education.

In Australia, one of the initiatives to emerge as a result of reviews into initial teacher education was the Hub School partnerships programme. Funded by the New South Wales (NSW) State Government, this partnership aimed at fostering a collaborative relationship between a cluster of schools and a university partner. The focus of the programme was to develop innovative ways to improve the professional experience of pre-service teachers, whereby the collective knowledge garnered from the various Hub Schools partnerships across the state would inform and influence teacher education reform.

The research reported here provides an evaluation of the first prototype developed between one Hub School and their partner university located in Sydney, Australia. This union is known as inSIDE, whose overarching objective was defined by the inSIDE leadership team as transformative professional learning which enables futures-focused learning. 
The process to achieve the desired outcome was developed around the principles of improvement science, with the research findings from the evaluation of the first prototype and subsequent lessons learned being the focus of this paper. To situate the inSIDE programme, this paper commences with an overview of different models of school-university partnerships operating both nationally and internationally. This paper next presents findings of the reviews into teacher education, which led to the development of the Hub School partnerships, and proceeds to examine the role of improvement science to inform the inSIDE programme. What follows is an evaluation of the first prototype, with recommendations for future school-university partnerships provided.

\section{Literature Review}

Internationally, school-university partnerships assume various models. As summarised by McMahon et al. (2015), the two entities can maintain separate roles; focus on pedagogic relationships; or, develop collaborative models. These approaches represent a continuum of school-university partnership applications. Most commonly, in countries such as Australia, Finland and Singapore, the route to gaining qualifications as a classroom teacher is predominately through university education, with opportunities for school-based professional experience available during this period of study. In contrast, the UK has moved away from initial teacher training at university towards school-based and school-led training (Mutton, Burn, \& Menter, 2017; Woodbury, 2017). An example of a programme at one end of the partnerships continuum is the Cambridge Partnership model, which offers an immersive approach to the training process controlled by schools, now operating without a university partner (Yeigh \& Lynch, 2017). Other international examples that take a more collaborative and integrated approach have been described, such as in Alberta, Canada, where Collins and Ting (2017) describe a successful school-university partnership in which two university subjects were delivered in an elementary school on a daily basis for two weeks.

The push for effective school-university partnerships in Australia has a decade-long history, evidenced in the Australia Government's (2007) 'Top of the Class' report and initiatives such as the Smarter Schools National Partnership's (2008) 'Improving Teacher Quality' programme (Bloomfield \& Nguyen, 2015). However, according to McLean Davies et al. (2013), 'despite these recommendations articulated over a 30-year period, little has been done to tackle these concerns in teacher education courses' (p. 94). Instead, pockets of innovative change to traditional initial teacher education have emerged. In Melbourne, Australia, a Master of Teaching programme at the University of Melbourne was specifically designed to address the persistent criticisms of teacher education (Darling-Hammond, 2017; McLean Davies et al., 2013) using a clinical framework in which pre-service teachers are supported by a mentor teacher and a clinical teaching specialist. Central Queensland University also introduced a Bachelor of Learning Management as an alternative to traditional initial teacher education. This program has forged strong partnerships with schools with a focus on the future, networks and partnerships, pedagogy and essential professional knowledge (Yeigh \& Lynch, 2017).

In an Australian context, where this research was conducted, three reports into teacher education contributed to the NSW Department of Education Hub School partnership initiative: the first is ACER's (2014) 'Best Practice Teacher Education Programs and Australia's Own Programs' report, and the second is the 'Action now: Classroom ready teachers' (Teacher Education Ministerial Advisory Group [TEMAG], 2014). The third report is 'Studying the Effectiveness of Teacher Education' by Mayer et al. (2015). The resulting recommendations highlighted the need for clearly articulated standards for teacher education programmes, and to identify candidates who possess a combination of personal attributes suited to the profession as well as the necessary academic skills (ACER, 2014). Table 1 summarises the key findings of the ACER (2014) report regarding effective initial teacher education programmes, the mechanisms to support enrolment of quality teaching candidates, and, in contrast, areas of concern for Australia's teacher education 
Table 1. Key Findings of the 'Best Practice in Teacher Education Programs and Australia's Own Programs' Report (ACER, 2014)

\begin{tabular}{|c|c|}
\hline Key Findings of the 'Best Practice in Tea & Education Programs and Australia's Own Programs' Report (ACER, 2014) \\
\hline \multirow{8}{*}{$\begin{array}{l}\text { Characteristics of effective teacher } \\
\text { education }\end{array}$} & Coherence \\
\hline & Strong core curriculum \\
\hline & Extensive, connected clinical experiences \\
\hline & Well-defined standards of professional knowledge and practice \\
\hline & Explicit strategies \\
\hline & An inquiry approach that connects theory and practice \\
\hline & Strong school-university partnerships \\
\hline & Assessment based on professional standards \\
\hline \multirow{5}{*}{$\begin{array}{l}\text { Mechanisms to support quality of teaching } \\
\text { entrants } \\
\text { Highly regarded teacher education } \\
\text { programmes use policies and mechanisms } \\
\text { in relation to: }\end{array}$} & $\begin{array}{l}\text { Recruitment into the programme by making it a lucrative option for high } \\
\text { achievers }\end{array}$ \\
\hline & Ensuring demand meets supply \\
\hline & Having high standards for gaining admission into the programme \\
\hline & $\begin{array}{l}\text { Regulating the accreditation of, and putting in place rigorous systems for, } \\
\text { institutions to be considered eligible to administer teacher education } \\
\text { programmes }\end{array}$ \\
\hline & $\begin{array}{l}\text { requiring high levels of assessment and mentoring over time as the graduate } \\
\text { transitions into their job }\end{array}$ \\
\hline \multirow{7}{*}{$\begin{array}{l}\text { Areas of concern for Australia's teacher } \\
\text { education }\end{array}$} & Weak application of national standards \\
\hline & Poor public confidence in initial teacher education \\
\hline & Demonstrated evidence of poor practice in a number of programmes \\
\hline & $\begin{array}{l}\text { Insufficient integration of teacher education providers with schools and } \\
\text { systems }\end{array}$ \\
\hline & Inadequate application of standards for pre-service teachers \\
\hline & Insufficient professional support for beginning teachers \\
\hline & $\begin{array}{l}\text { Gaps in crucial information about the effectiveness of initial teacher education, } \\
\text { including workforce data }\end{array}$ \\
\hline
\end{tabular}

The ACER (2014) findings resulted in the formulation of five key proposals and 38 recommendations. The five proposals are:

- Strengthened national quality assurance process

- Sophisticated and transparent selection for entry to teaching

- Integration of theory and practice

- Robust assurance of classroom readiness

- National research and capability.

Conversely, respondents in the longitudinal study report by Mayer et al. (2015) ('Studying the Effectiveness of Teacher Education') identified the value of professional experience placements. Overall, 95 per cent said the skills developed during these experiences were significant, while 90 per cent felt better prepared. Those who stated they had undertaken an internship also thought themselves more prepared. These findings align with the key directions articulated in the TEMAG (2014) report, particularly that there should be an integrated system wherein 'higher education provides, school systems and schools working together to achieve strong graduate and student outcomes. Partnerships ensuring initial teacher education meets the needs of employers and schools. Professional experience integrated with provider-based learning.' (p.vii).

The ACER (2014), TEMAG (2014) and Mayer et al. (2015) reports have together been instrumental in generating the demand for changes to the ways teacher educators think about, and do, teacher education. The above has informed the inSIDE programme, including its five core drivers, which are identified and described in detail in Section 3. 


\section{3. inSIDE: An Innovative School-university Partnership}

The Hub School in this study is a secondary school located in Sydney, Australia. With around 1,250 students enrolled (with equal male-female enrolments), approximately 38 per cent of the student population is from a language background other than English. In addition, 86 per cent of the students enjoy middle-high socio-educational status (Australian Curriculum, Assessment and Reporting Authority, 2019). This school entered its partnership with a university holding a pre-existing mission statement. According to this vision, the school 'seeks to empower individual learners through the creation of a future-focused learning environment prioritising collaborative and innovative practice'. In collaboration with staff, students and parents, the school developed three strategic directions that are clearly aligned with the Hub School partnerships aims to support innovative practices and joint partnerships. These include:

- Engagement - student engagement through innovative quality teaching and learning practices

- Wellbeing - holistic development of students and staff through wellbeing, capabilities development and leadership

- Learning community - a collaborative and connected community of future-focused learners.

Building on the Hub School's existing vision, the inSIDE leadership team making up the school-university partnership captured the purpose of the inSIDE programme through four statements:

- There is a need to improve the experiences of pre-service teachers.

- There is a need to improve teacher quality.

- There is a need to implement future-focused learning.

- This is a flagship programme and demands radical thinking and experimentation.

A fishbone diagram of the overarching problem statement was then developed. Essentially, this tool 'visually represents a group's causal systems analysis (sometimes known as a cause-and-effect diagram or an Ishikawa diagram)' (Bryk, Gomez, Grunow \& LeMahieu, 2015, p. 198). Therein, the overarching problem was stated as 'teachers ... coming to schools from a traditional teaching education model having a very narrow, content focused approach on their role as a teacher and their place in the educational environment/school'.

This initial planning was more precisely articulated and formally presented in the form of a driver diagram. According to Bryk et al. (2015), this tool:

Organises the various changes the network is trying out. It gives participants a common language as they build toward a solution to a shared problem. The diagram focuses on a small set of hypotheses about key levers for improvement, specific changes that might be attempted for each, and the interconnections that may exist among them. (p. 73)

The driver diagram comprised a key aim and five primary drivers (see Figure 1). This aim explained that 'in two years' time, we will have a sustainable, well-researched, measurable professional learning process that transforms the teacher education experience to better meet future learning needs'.

The final wording of the five core drivers was as follows:

Core Driver 1: Develop and maintain sustainable processes.

Core Driver 2: Analyse and respond to complex data.

Core Driver 3: Support collaborative learning.

Core Driver 4: Develop purposeful, professional learning.

Core Driver 5: Develop as a flexible, supportive and evolving programme. 


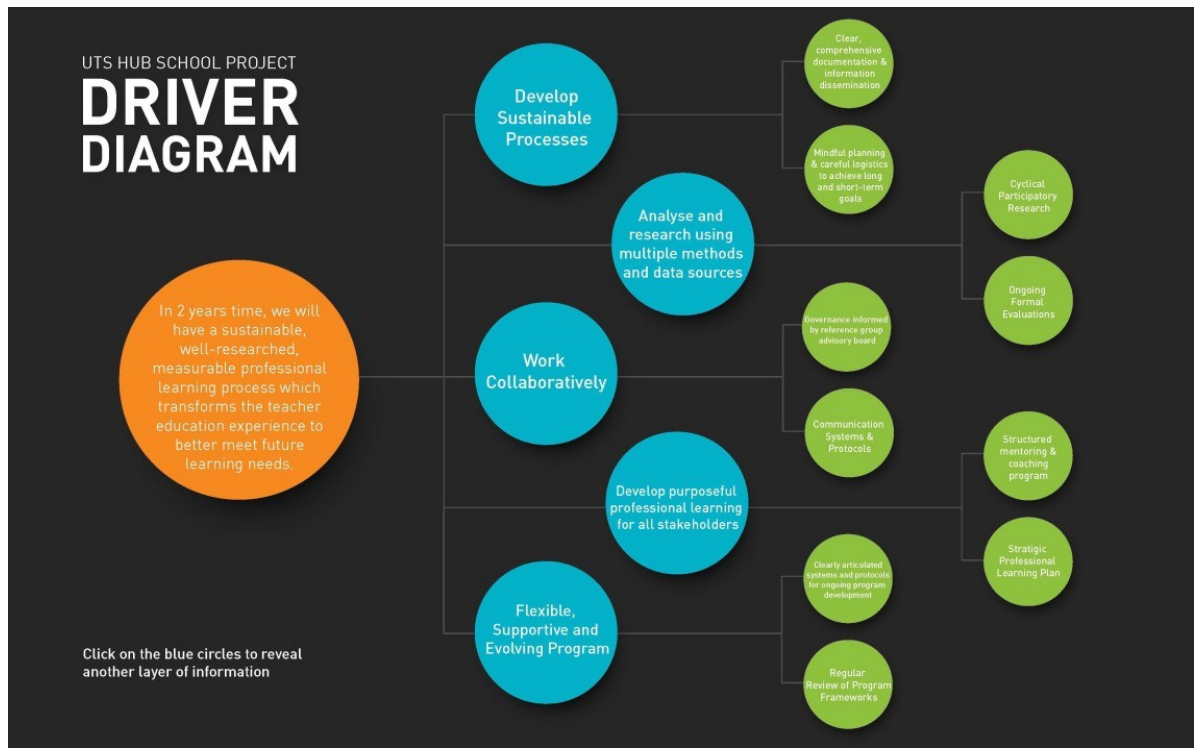

Figure 1. inSIDE Driver Diagram (Created by the inSIDE Leadership Team)

Fishbone diagrams and the development of specific drivers are fundamental features of improvement science. Improvement science (as described in Section 4) was introduced to the project by a professor at the partner university, who provided the foundation for the design and delivery of the Hub School and university partnership. Hence, the project was titled 'inSIDE'.

\section{4. inSIDE: Improvement Science}

While improvement science has a history of success in transforming learning opportunities in fields outside education, the intersection of systems of understanding with the practical implementations of improvement remains under-researched in the field (Lewis, 2015). When improvement science has been applied to educational contexts, as Bryk et al. (2015) succinctly stated, it assists in making schools 'better at getting better' (p. 10). According to them:

Improvement science is a methodology that disciplines inquiries to improve practice. Undergirding it is a distinctive epistemology about what we seek to learn and how we may come to understand it well. Particular acts of inquiry are improvement research projects. These projects aim for quality improvement ... Since improvement research is an iterative process often extending over considerable periods of time, it is also referred to as continuous improvement. $(2015$, p. 10)

To facilitate improvements in education, it is suggested that two bodies of knowledge are required. The first is 'basic knowledge from the discipline of education' (Lewis, 2015, p. 54) and the second is 'a system of profound knowledge' (Deming, cited in Langley et al., 2009, 75). The definition of profound knowledge, as outlined by Deming, is 'the interplay of the theories of systems, variation, knowledge and psychology' (Langley et al., 2009, p. 75).

Langley et al. (2009) also drew on Deming's understanding of profound knowledge extensively, explaining that it comprises four elements:

- Appreciation for a system - this, they argue, is about understanding how all the parts of an organisation fit together to form a system. These parts then work together to achieve a common goal (p. 77).

- Understanding variation - some variation in data relates to 'common causes' and other variations relate to 'special causes' (pp. 79-80). Common causes are 'those that are inherent in the process (or system) over time, affect everyone working in the process, and affect all outcomes of the process' (p. 79). Special causes 'are not part of the process (or system) all the time, or do not affect everyone, but arise because of specific circumstances' (p. 80).

- Building knowledge - when considering 'improvement' it is important to measure the outcome of any change by measuring the results that take. The easiest way to do this is by stating a theory or a hypothesis at the outset. This will assist in testing predictions and, thus, understanding how to further improve in future. The most efficient way of doing this is through the Plan-Do-Study-Act (PDSA) cycle (pp. 81-82). 
- Human side of change - this recognises differences in the way people behave, and how they relate and interact with one another and within a system. Essentially, 'it helps us understand the motivations of people and their behaviour' (p. 83).

The improvement science cycle of PDSA provides a useful framework, which is integral to building knowledge. In their work with the Carnegie Foundation, Bryk et al. (2015, p. 122) have modified Langley's original PDSA cycle descriptors slightly:

- Plan: Define the change. Make predictions about what will happen as a result. Design a way to test change on an appropriate scale.

- Do: Carry out the change. Collect data and document how change was implemented.

- Study: Analyse the data. Compare what happened to predictions. Glean insights for the next cycle.

- Act: Decide what to do next based on what you learned. Abandon the idea? Make adjustments? Expand the scale?

Three questions should next to be asked to implement the PDSA cycle:

- What are we trying to accomplish?

- How will we know that a change is an improvement?

- What change can we make that will result in improvement? (Langley et al., 2009, pp. 89-96)

The leadership team subsequently applied principles of improvement science to develop the framework that underpinned the inSIDE design and delivery. This resulted in a future-focused, innovative approach to reform teacher education using clearly articulated problem statements and core drivers.

\section{Research Design}

In line with the study phase of improvement science, towards the conclusion of the first inSIDE prototype a researcher from the partner university, who had not been involved in the first prototype, was engaged to evaluate the outcomes of the first year towards the five core drivers. This evaluation was responsive; that is, the views and experiences of various stakeholders were incorporated, and the research took account of three factors: implementation, context and the human factor (Hartas, 2010).

An evaluation research methodology was applied. More specifically, the goal attainment model of evaluation research was used, which sought to determine the extent to which a programme is achieving its formal goals (Rubin \& Babbie, 2010) - in this case expressed as five core drivers. Two research methods were employed to achieve the research objectives: focus groups and document/artefact analysis.

\subsection{Focus Groups}

Focus groups are conducted in similar way to interviews, but with a group of people rather than one on one. Focus groups can offer a rich dataset based on the fact that participants in the discussion are likely to bounce ideas off each other when discussing a topic. The conflicting opinions or in-depth description of a shared experience are also likely to generate robust data (Travers, 2006, p. 106). Seven focus groups were held and the findings fed into a broader evaluation day with the members of the leadership team.

The focus groups were conducted using a lessons-learned approach that allows for both formative evaluation (monitoring and continuous improvement) and summative evaluation (project evaluation and information for future projects). Within this approach, three questions were posed to interview participants:

- What is working well?

- What can we improve upon?

- What should we do differently?

These questions were asked with participants' attention directed towards each of the five core drivers of the inSIDE programme previously outlined.

\subsection{Document Analysis}

Themes emerging from the focus groups were then triangulated through analysis of documents and artefacts that had been created since the inception of the programme to the date of evaluation. These included minutes of meetings, planning documents, photos of planning boards and email correspondence. These resources were particularly 
enlightening, as they emerged in situ and systematically captured the interests, goals and direction of the project in sequential order (Cohen, Manion \& Morrison, 2011).

\subsection{Ethics}

The research received Human Research Ethics approval (no. ETH16-0896). Informed consent was also obtained from each participant.

\subsection{Participants}

As detailed in Table 2, there was a total of 49 participants, 31 of which were from the Hub School, and 18 from the partner university. The latter included six academic staff, three administrative staff and nine pre-service teachers enrolled in a Master of Teaching degree. The pre-service teacher participants are referred to hereafter as the inSIDE pre-service teachers.

Table 2. Participant Summary

\begin{tabular}{lll}
\hline Hub School & Partner university & Pre-service teachers \\
\hline Principal $(n=1)$ & $\begin{array}{l}\text { Head of School of Education/Master of } \\
\text { Teaching coordinator }(n=1)\end{array}$ & $\begin{array}{l}\text { Master of Teaching students } \\
(n=9)\end{array}$ \\
Executive staff $(n=4)$ & Partnerships liaison academic $(n=1)$ & \\
Mentor teachers $(n=9)$ & Subject coordinators $(n=2)$ & \\
Supervising teachers $(n=17)$ & Other academic staff $(n=2)$ & \\
& Administrative staff $(n=3)$ & \\
\hline
\end{tabular}

\subsection{Overview of inSIDE Structure}

The leadership team comprised Hub School staff (school principal and four executive staff members) and partner university staff (Head of the School of Education; Master of Teaching coordinator; school partnership liaison academic; senior lecturer; and a professor, who held joint appointment at the partner university and in the UK). This team conceptualised the inSIDE programme and developed the comprehensive purpose and goals therein.

Following development of the core drivers, the next step was to recruit pre-service teacher participants. A call for expressions of interest in the inSIDE programme was extended to all new enrolments in the Master of Teaching degree at the partner university. This is a two-year postgraduate degree that prepares individuals who already hold an undergraduate degree to work as secondary school teachers. Students then expressed interest by submitting a formal statement, with successful applicants undergoing a panel interview comprising partner university and Hub School staff. Ten students commenced the programme, nine of whom completed the first year.

The first inSIDE prototype was developed with a view to embed the pre-service teachers into the Hub School, thus, enabling their immersion into school life. Concurrently, they also completed two university subjects from within the high school, rather than on campus. The programme also included weekly learning labs at the Hub School, which were facilitated by a professor from the partner university. Documents developed by the inSIDE leadership team state that these weekly labs were intended to "provide an opportunity for expert input, for "check-ins" to share student learning and experience and to "engage in the double loop learning" necessary to improve the core job of learning to facilitate futures-focused learning'.

\section{Findings}

The findings are organised around four of the five core drivers developed by the inSIDE leadership team. The nature of qualitative data and phrasing of the core drivers meant that these drivers could not be neatly analysed in isolation, and that two of the core drivers were examined concurrently. The four core drivers are listed in three groupings, as follows:

- Core Driver 1: Develop and maintain sustainable processes.

- Core Driver 3: Support collaborative learning, and Core Driver 4: Develop purposeful, professional learning.

- Core Driver 5: Develop as a flexible, supportive and evolving programme.

At the time of evaluation, there were limited data to address Core Driver 2. Thus, this driver is omitted from the paper. 


\subsection{Core Driver 1: Developing and Maintaining Sustainable Processes}

Improvement science identifies the need to understand how all the parts of an organisation fit together to form the system. To understand the effect of the first prototype cycle in relation to the inSIDE system, six themes emerged from the data. These were participation, documentation, communication, time and space. Each affected the sustainability of the programme.

\subsubsection{Participation}

For any system to function cohesively and effectively the component parts must be considered. The diversity of experiences and philosophies that underpin the practices of the system members increased its complexity. The voluntary nature (or not) of participation by staff was a contributing factor to the outcomes of the first prototype.

Nine teachers from the Hub School took on a mentoring role. Mentor teachers' participation was voluntary and constituted the first relationship established between inSIDE pre-service teachers and the Hub School. These teachers spent the initial weeks at the school with their mentor teachers, who were from outside their faculty areas. Each mentor took a different approach to their mentoring role, with some having their inSIDE student shadow them around the school, while others arranged for the inSIDE pre-service teachers to engage in a range of activities with different teachers across the school. The mentor teachers were highly positive about their role in the programme, and the inSIDE pre-service teachers were likewise complimentary of the role of their mentor. Mentor teachers said their motivation for engaging in the project was aimed at preparing future teachers to succeed and excel in the profession.

In contrast, teachers who acted in a supervisory role for the inSIDE pre-service teachers felt their participation was not voluntary. This was due to all nine inSIDE pre-service teachers being located in only two faculty areas. This placed great demand on these two faculties, particularly as each of the nine inSIDE pre-service teachers were allocated two supervisors in an attempt to increase the diversity of teaching they would observe and practise in their faculty areas.

\subsubsection{Documentation}

The leadership team was highly successful in capturing and sharing the authentic progress of the first prototype through minutes of meetings, visual capture of planning boards and collation of formal documents (e.g., invitation letters to potential students). As evidenced by the meetings, the leadership team identified many of the complex issues that needed to be addressed in this ambitious approach to revising teacher education.

At the conclusion of the first prototype, inSIDE pre-service teachers held strong views that formal documentation was required to guide their participation. While there was acceptance that unknowns were inevitable, given this was a pilot iteration, the widely held view was that by the conclusion of the first year there should be distribution of formal documentation to guide future years. The inSIDE pre-service teachers desired a level of documentation in line with traditional subject outlines produced by the university, but written in terms of the entire two-year inSIDE programme and clearly outlining the requirements for participation in terms of time and dates, details of activities to be completed (e.g., observations, team teaching and independent teaching), and assessment tasks. This form of detailed documentation would be vital if students become highly anxious about their participation in the programme.

The supervising teachers from the Hub School also required more traditional documentation in the form of a practicum handbook. There was consensus that formal documentation is necessary to enable effective communication between supervising teachers and inSIDE pre-service teachers around their participation in teaching and extracurricular activities, the time period for engagement and reporting processes.

While mentor teachers did not express a specific need for explicit guiding documentation, for future iterations, they sought greater guidance on the types of activities they should engage in with their mentee. This included the time frame for their involvement across the programme as a whole to maximise inSIDE pre-service teachers' learning outcomes.

\subsubsection{Communication}

Issues around communication were evident in the minutes taken of meetings around midyear of the first prototype and by the time the focus groups occurred later in the year. Evidently, communication was a primary factor creating unease within the system. The inSIDE pre-service teachers described frustration with the 'trickle-down information system', which left them as conduits for information to the supervising teachers. The Hub School teachers also desired more in-depth communications about the inSIDE pre-service teachers. As they were undertaking a postgraduate degree, these students came to inSIDE with diverse educational backgrounds and life experiences. Teachers (particularly mentor teachers) wanted greater detail about the inSIDE pre-service teachers' backgrounds, their educational experiences and the like. It was apparent that some Hub School teachers assumed their inSIDE counterparts had teaching backgrounds and were taken aback at how raw the inSIDE pre-service teachers proved to be. 
Communication tensions between the Hub School and Partner University led to concerns being raised regarding a perceived defensiveness, and perhaps lack of regard, from university staff towards the project. This tension was viewed by Hub School staff as the university's 'fear of change', while the typical view held by partner university staff related to being 'time-poor' and that the initiative was 'a huge investment for nine students'. Notably, with the exception of one academic staff member, there was no allocation of time or funding for any other partner university (academic and administrative) staff.

Email also proved extremely ineffective as a communication method for collaborative teams working across two locations. A limitation at the organisation levels is that different communication and online collaboration tools were used at the Hub School and Partner University, which prevented a more efficient means of electronic communication being utilised.

\subsubsection{Commitment}

The inSIDE pre-service teachers valued the strong bonds they had built with their peers and felt the collaborative relationships were the most beneficial aspects of this project. An important contributing factor in building these bonds was the weekly check-ins that formed part of the learning lab sessions. Check-ins involved the inSIDE pre-service teachers meeting weekly at the Hub School with the partner university professor to reflect on, and examine, their experiences over that week. This enhanced their commitment to the project over the first year.

However, the time commitment for inSIDE pre-service teachers was significant. For university students engaged in the traditional programme, coursework in their Professional Experience subject (one of the subjects the inSIDE pre-service teachers completed at the Hub School) required 10 hours of on-campus workshop sessions and a professional experience placement that equates to 28 days (five observation days and 23 teaching days). The second subject delivered at the Hub School (a research-focused elective) was credited as an 18-hour subject, plus additional reading and writing tasks. In comparison, the inSIDE pre-service teachers report having invested over 60 days and, in some cases, over 70 days attending the Hub School as part of the inSIDE programme. This did not include the additional study time to complete assignments.

While many teachers and teacher educators would view this time in schools as a significant advantage in becoming an effective educator, by the conclusion of the first prototype the inSIDE pre-service teachers were becoming overwhelmed by their commitment to the programme. Notably, some were exhausted from juggling travel (in some cases up to two hours each way on public transport), employment commitments and other university commitments (classes and assignments). Many felt that despite the real benefits of the programme towards building their teaching competence, the workload was unsustainable. inSIDE pre-service teachers expressed disappointment that there was not more formal recognition for the time and effort put into the programme. They also wondered if and how the programme would contribute to increased employability.

From the partner university perspective, the programme was also expensive to deliver. There was the cost of personnel, with two or three staff members travelling to the Hub School for leadership meetings each month. The partner university's school partnerships liaison academic was employed at the university on a fractional appointment and spent a significant portion of this time engaged in activities related to the inSIDE programme. A senior lecturer (School of Education) was also engaged in many hours of preparation work, such as recruiting and interviewing potential participants, while a professor attended the Hub School on Thursdays for approximately a half year to engage in weekly inSIDE learning labs. With only nine students enrolled, this did not constitute a recognised university teaching allocation, which made sustainability more complex. With no allocated partner university budget for the delivery of the programme, it operated on the goodwill of participants who valued the potential of the programme. Focus group data suggest it is not only the culture of the university that needs to change, but also the mindset of practising teachers and university students who have pre-existing expectations for the programme to reflect elements of the traditional pre-service programme delivery that occurs at university.

\subsubsection{Time}

The complexity of the system was highlighted through time limitations. At a pragmatic level, the limited time available for inSIDE activities was exacerbated by the official university timetable, compared with the secondary school year. This is also a concern in relation to planning, where university academic staff availability is higher across periods when Hub School staff are on school holiday breaks. The number of non-teaching weeks at the university also greatly reduces the available weeks for inSIDE pre-service teachers' mandatory attendance and participation at the Hub School. 


\subsubsection{Space}

The physical distance between the university and school (being $24 \mathrm{~km}$ apart, along often congested roads with no direct public transport) proved prohibitive to many of the desired collaborative activities taking place. While initial goals included ongoing and sustained collaboration between school and university, physical distance prevented regular meetings with academic staff and teaching staff, and was instead limited to the leadership team. The physical divide between university and school also prevented regular informal 'workplace' conversations and widespread collaborative planning opportunities, which might have otherwise occurred if co-located. The partner university's focus group data and minutes of meetings indicate that consideration of the potential of a 'third space' to facilitate collaborative relationships had been explored, but this potential did not emerge in the first prototype.

Further, the physical space at the Hub School was problematic given the high number of inSIDE pre-service teachers located in two school faculties. Teachers mentioned that the extra bodies and noise in staffrooms negatively contributed to their experience of the programme. Several Hub School teachers reported issues concerning staffroom etiquette (e.g., noise), while others expressed concern that having the inSIDE pre-service teachers regularly present in the staffroom prevented them from engaging in lesson preparation and other work-related activities.

\subsection{Core Driver 3: Supporting Collaborative Learning; and Core Driver 4: Developing Purposeful, Professional Learning}

The degree to which Core Drivers 3 and 4 were being achieved in the first prototype are explored through three themes: Hub School cross-faculty mentoring, subject development and delivery, and inSIDE pre-service teachers' progress towards professional standards and as future-focused teachers.

\subsubsection{Cross-Faculty Mentoring}

In terms of teacher professional development, the mentoring component of the inSIDE programme resulted in positive gains for mentors who engaged in a professional development workshop delivered at the Hub School by academics from the partner university. A novel approach of the inSIDE programme was that the mentors did not originate from the same faculty area in which the inSIDE pre-service teachers were preparing to teach. The opportunities for these pre-service teachers to observe and work in faculties outside their area of teaching specialisation enabled them to observe practices that are less common in their own fields. These experiences also exposed some mentor teachers to practices that they would not normally employ in their lessons, as the inSIDE pre-service teachers approached teaching and learning episodes from markedly different perspectives.

These opportunities were valuable for both mentors and mentees. This aspect of the programme represents an area for further exploration for teacher educators and in terms of teacher professional development. In this sense, mentors expressed a desire to have even greater involvement in the inSIDE programme and said they would relish additional opportunities to engage in both formal and informal activities with their mentees to continue to guide their induction into the profession. They also desired to work more collaboratively with inSIDE pre-service teachers and university academic staff.

Capturing and sharing the components of effective mentoring relationships and these rich experiences has the potential to contribute to both mentor and mentee pedagogical awareness. However, this should not be too prescriptive and must enable flexibility to develop and evolve in terms of the unique characteristics of each mentor-mentee relationship, including the emerging needs of each inSIDE student. As such, this may guide their progress in a supportive manner and assist in addressing any problems as they arise. The mentor-mentee relationship also proved essential in addressing concerns that arose later in the year regarding the progress two inSIDE pre-service teachers were making with their classroom teaching.

\subsubsection{Subject Development and Delivery}

At the commencement of the programme, a number of subjects from the Master of Teaching degree were proposed by the partner university as appropriate for delivery at the school. However, limited communication between academic staff (subject coordinators) responsible for overseeing the subjects and ultimately submitting inSIDE pre-service teachers' grades and staff charged with delivery of the subjects at the school caused some tensions. This was, in part, due to retrofitting subjects developed for a traditional teacher education model to the innovative inSIDE delivery mode.

During focus groups, Hub School teachers expressed interest in being involved in the development and delivery of subjects, suggesting ways that inSIDE pre-service teachers' activities could meaningfully contribute to school practices. This included inSIDE pre-service teachers being involved in programming, with associated tasks to 
contribute meaningful content to faculty programmes. Developing and delivery of such subjects would be beneficial to the programme and to Hub School teachers' professional development.

At the time of conducting the focus groups, the inSIDE pre-service teachers were experiencing high levels of anxiety about completing their independent research project, which was the second subject delivered at the Hub School. Focus group data from the inSIDE pre-service teachers revealed their concern that this subject was heavily focused on research, whereas they had entered the inSIDE programme on the basis that it would be practice-oriented. The delivery of university subjects by university staff appears to have perpetuated the school-university divide and continued to send the message to inSIDE pre-service teachers that practical teaching is completed by the teachers, while academic work is completed by university staff.

The key stakeholders held very different views on the number of university subjects that should be delivered onsite at the school. Many school staff envisaged full immersion and all subjects to be delivered at the Hub School, while inSIDE pre-service teachers felt that only some subjects lent themselves to delivery as part of the inSIDE programme. They preferred on-campus delivery of teaching methods subjects because this increased their exposure to a broader range of teaching strategies than they may experience when working with supervising teachers during their time at the Hub School. Along these lines, several teachers alluded to their desire for inSIDE pre-service teachers to inform and improve their practices by bringing to the school new strategies and techniques learned at university, which would require the inSIDE pre-service teachers to engage in experiences beyond the Hub Schools.

\subsection{3 inSIDE Pre-Service Teachers' Progress Towards Professional Standards And as Future-Focused Teachers}

The nine inSIDE pre-service teachers represent the diversity of professionals working in many Australian schools in terms of gender, age and cultural background. Indeed, their personal experiences as pioneers of the inSIDE programme also reflected this diversity.

Evaluation of the progress of inSIDE pre-service teachers varied considerably across the stakeholders, with some supervising teachers of the view that certain inSIDE pre-service teachers were not adequately prepared. By contrast, one inSIDE student noted the following observation:

I'm definitely more confident ... significantly, definitely ... I think it helped me because the [secondary] students ... didn't actually identify me as a prac teacher because I was there for so long and a lot of the time they just thought I was actually just a new teacher ... because they would always see me in the staffroom and so they knew I wasn't a prac teacher ... That helped a lot with management.

All inSIDE pre-service teachers concurred that the rapport they had with secondary school students was a key benefit of the programme. This greatly contributed to their positive teaching experiences at the Hub School.

The partner university's school partnership liaison academic (who was previously employed as a school principal) concluded that the nine inSIDE pre-service teachers represented a typical breakdown of student achievement that would be demonstrated after a period of block teaching. Therein, three of them exceeded expectations, four met expectations and two were at risk of not meeting requirements. It appears that the possibility of inSIDE pre-service teachers failing their practical teaching evaluations, or any coursework, was not considered until the issue arose during the block of intensive teaching.

The traditional Master of Teaching mode taught on campus saw students demonstrate achievements of graduate-professional standards through successful completion of formally accredited subjects that explicitly articulate how subject content and assessment tasks relate to the Australian Professional Standards for Teachers (APST). Minutes of meetings throughout the first prototype suggest the leadership team considered the use of formal assessment tools. Research data suggest the need to revisit the potential of tools for student self-assessment and alternate ways to capture inSIDE pre-service teachers' achievements of accredited subjects and course objectives to ensure they are meeting designated professional teaching standards.

The inSIDE pre-service teachers voiced a considered view: remaining at this one school for professional experience or transferring to a nearby secondary school (one of the Hub School partners) for the next professional experience may not provide them the same breadth of experience as working with students from other socio-economic and ethnic backgrounds, which their on-campus peers would otherwise experience.

\subsection{Core Driver 5: Developing as a Flexible, Supportive and Evolving Programme}

In the period following the formal evaluation, documentary evidence was available that clearly demonstrated the programme was evolving as a result of lessons learned from the first prototype. In the following year, the focus was on 'several sub-projects, each aimed at addressing issues identified in the first prototype' (Report from an academic from 
the partner university, employed outside the School of Education). The first sub-project included a different Master of Teaching subject (Inclusive Education) being taught at the Hub School by the school's special education teacher, rather than a university academic. In this model, the nine content areas covered by on-campus students were available to the inSIDE pre-service teachers as online lectures and readings, which they could access at times that aligned with the activities naturally occurring at the Hub School. This approach ensured consistency of content across the on-campus and inSIDE cohorts. Through the Hub School delivery of the Inclusive Education subject, inSIDE pre-service teachers:

Not only learned about the theory and practice of Inclusive Education but also met students receiving learning support and gained an understanding of pivotal roles in a school context, such as the Learning and Support Teacher, School Counsellor, Head Teacher, [and] Support Teacher Vision. (Report from an academic from the partner university, employed outside the School of Education).

The second sub-project entailed the development of two new subjects forming part of the pool of electives available to students in the Master of Teaching. One was titled 'Teacher as Innovator: Planning and Prototyping Future-focused Learning Design', and the second was 'The Innovative Teacher: An Introduction to Future-focused Teaching Design'. This subject was designed to equip students to employ innovative and engaging practice. Therein, students were provided opportunities to research, design, implement and measure the outcomes of innovative practice using the problem-focused approaches of improvement science. The approach was inquiry-based, wherein students collaborated and shared with peers and engaged in critical dialogue with experienced teachers. Delivery was multimodal across the Hub School and Partner University.

\section{Discussion}

Applying principles of improvement science, the inSIDE programme was designed to address several priorities raised in the ACER (2014), TEMAG (2014) and Mayer et al. (2015) reports. Some design elements reflect approaches taken nationally and internationally, aimed towards improving initial teacher education, while others were unique to the context of this particular school-university partnership. Although not specifically applying principles of improvement science, the Master of Teaching model at the University of Melbourne articulated a clear driver statement with goals aligned to the inSIDE programme - that is, to 'produce a new generation of teachers ... who are interventionist practitioners, with high-level analytic skills and capable of using data and evidence to identify and address the learning needs of individual learners' (McLean Davies et al., 2013, p. 93).

The application of principles of improvement science during the planning phase enabled the leadership team to clearly define the change they envisaged for improvements to teacher education. In turn, the leadership team identified the specific issues affecting teacher education and subsequently articulated the core drivers of the project. Acknowledging the complex system, which integrates the school and university context, the team developed an ambitious, future-focused programme. Findings highlighted the complexities involved when two organisational structures collaborate, including the need for greater systemic flexibility to enable vision and change to be enacted.

Focusing on the literature, Walsh and Backe (2013) identified four characteristics of effective school-university partnerships. These included shared conceptual understanding, mutuality in roles and relationships, sound operational strategies, and evaluation of both the partnership and its outcomes. Meanwhile, Mutton et al. (2017) concluded that effective school-university partnerships utilise expertise from across a collaboration; are built on mutual respect and a shared vision, as well as clearly defined and agreed roles; require a critical mass of expertise; and facilitate opportunities across a range of settings and contexts and types of expertise. As discussed, the inSIDE programme reflects and/or addresses each to varying degrees.

Drawing on lessons learned from the first prototype, the inSIDE leadership team reflected on the subjects being delivered through the partnership. Collins and Ting (2017) suggested there should be 'opportunity for integration among subjects to arise naturally rather than being contrived and pre-planned to fulfil some popular pedagogy for integration' (p. 8). Essentially, they envisaged 'enacting all coursework as practice, inquiry, content, and reflection, within a school' (p. 8). However, this remains a challenge in all models, particularly given the accreditation requirements of educational bodies that (in the context of this study) require universities to demonstrate how the teaching and learning experiences and the associated assessments enable new teachers to meet the APST. There are also concerns that school-directed programmes may only meet the more practice-oriented outcomes of these standards (Mutton et al., 2017).

Further, Yeigh and Lynch (2017, p. 121) suggested one benefit of the partnership approach to initial teacher education is that pre-service teachers can expect a high level of individual support from the school as they journey through the 
training programme, due to the mentoring system involved. Indeed, a particular strength of the inSIDE programme was its innovative approach to mentoring, using mentors from different faculties to the faculty area in which each pre-service teacher specialised. This further enabled the pre-service teachers to benefit from the integration of different sources of knowledge (Mutton et al., 2017).

This aspect appeared particularly successful due to the voluntary nature of the mentors' participation. Also, as part of the inSIDE programme, the mentors undertook a mentoring workshop with university academics, which overcame limitations identified by others. This included failure to provide mentors with the skills required to be effective guides (Talbot, Denny, \& Henderson, 2018; Young, 2018).

Further, Collins and Ting (2017) recognised that in their partially integrated school-based teacher education programme 'the practical part of teaching continued to be the main focus and reflective thought still had to be encouraged — or even demanded. The divide [theory and practice], though mitigated, still remained' (p. 7). Thus, the inSIDE programme, although school-based and influenced, successfully addressed this by explicitly factoring in time for participants to become reflective practitioners during the weekly learning labs with the university professor - which proved another key strength of the programme.

The notion of 'growing your own' and the potential disadvantages involved in schools training teachers within their own limited context and specific ethos (as raised by Woodbury [2017]) aligns with the concerns voiced by the inSIDE pre-service teachers, who thought the diversity of their experiences would be limited by the Hub School arrangements. Full school immersion, without university input, also has the potential to perpetuate concerns raised by the Hub School teachers; that is, the pre-service teachers would not be bringing new ideas to school. Similarly, inSIDE pre-service teachers identified that having different lecturers at university offered a greater repertoire of pedagogical approaches than could be provided in a single-school faculty. For this, Yeigh and Lynch (2017) proposed an evidence-driven partnership model designed to better reflect the practical skills required by teachers, one in which the respective inputs from schools and universities are more balanced and immersive. Hence, the findings from evaluations of the first inSIDE programme prototype support this proposal.

\section{Conclusion}

Examining the progress towards four of the core inSIDE drivers using an external evaluation and acting on those 'lessons learned' demonstrates the application of the improvement science PDSA cycle. Timing of the focus groups occurred at a period when inSIDE pre-service teachers were experiencing high stress due to assignment commitments, both as part of the inSIDE programme and from undertaking subjects studied on campus. Had focus groups been conducted at a different time, different issues may have been the focus of participants. However, this research has enabled an honest account of the benefits and challenges of the inSIDE programme to emerge, as experienced by the key stakeholders.

Overall, this paper reports on a project that brought together two complex entities that hold a common goal: improve teacher preparation and, thus, increase the learning outcomes of school students. The catalyst for this research was a project compelled by a perception that Australian students were not achieving on global scale measures and were not demonstrating gains on national scales. This perception led to criticism of the quality of teaching that, in turn, questioned the quality of teacher education. A positive outcome of these criticisms was the statewide establishment of the Hub School partnerships, which provided funding to schools to collaborate with other schools and universities to explore ways to improve the quality of initial teacher education. As research into each of these partnerships continues to emerge, evolving models will contribute knowledge and understanding of the facilitators and barriers to effective school-university partnerships. In turn, this will eventually underpin an effective and sustainable approach to initial teacher education, which draws upon the knowledge and strengths of school- and university-based educators.

\section{Acknowledgements}

The author thanks her colleagues Professor Pam Ryan and Associate Professor John Buchanan for their useful feedback on this paper. 


\section{References}

Australia Council for Educational Research (ACER). (2014). Best practice teacher education programmes and Australia's own programmes. Canberra: Department of Education.

Australian Curriculum, Assessment and Reporting Authority. (2019). Retrieved from https://www.myschool.edu.au

Bloomfield, D., \& Nguyen, H. T. M. (2015). Creating and sustaining professional learning partnerships: Activity theory as an analytic tool. Australian Journal of Teacher Education, 40(11), 23-44. https://doi.org/10.14221/ajte.2015v40n11.2

Bryk, A. S., Gomez, L. M., Grunow, A., \& LeMahieu, P. G. (2015). Learning to improve: How America's schools can get better at getting better. Cambridge, MA: Harvard Education Press.

Buchanan, J. (2012). Telling tales out of school: Why former teachers are not returning to the classroom. Australian Journal of Education, 56(2), 205-217. https://doi.org/10.1177/000494411205600207

Cohen, L., Manion, L., \& Morrison, K. (2011). Research methods in education (7th ed.). Abingdon, UK: Routledge.

Collins, S., \& Ting, H. (2017). Integrated school-based teacher education: From apprenticeship to complex learning system. Complicity: An International Journal of Complexity and Education, 14(1), 3-15. https://doi.org/10.29173/cmplct28838

Darling-Hammond, L. (2017). Teacher education around the world: What can we learn from international practice? European Journal of Teacher Education, 40(3), 291-309. https://doi.org/10.1080/02619768.2017.1315399

Dinham, S. (2015). InSights: Issues and perspectives relevant to the development of an approach to the accreditation of initial teacher education in Australia based on evidence of impact. Paper prepared for the Australian Institute for Teaching and School Leadership. Retrieved from https://www.aitsl.edu.au/docs/default-source/default-document-library/ite-reform-stimulus-paper-03-dinham.pd f?sfvrsn=1dfcec3c_0

Hartas, D. (Ed.). (2010). Educational research and inquiry: Qualitative and quantitative approaches. London, UK: Continuum.

Ingersoll, R. M., \& Smith, T. M. (2003). The wrong solution to the teacher shortage. Educational Leadership, 60(8), 30-33.

Langley, G. J., Moen, R. D., Nolan, K. M., Nolan, T. W., Norman, C. L., \& Provost, L. P. (2009). The improvement guide (2nd ed.). San Francisco, CA: Jossey-Bass.

Lewis, C. (2015). What is improvement science? Do we need it in education? Educational Researcher, 44(1), 54-61. https://doi.org/10.3102/0013189X15570388

Mayer, D., Allard, A., Bates, R., Dixon, M., Doecke, B., Kline, J., ... Hodder, P. (2015). Studying the effectiveness of teacher education (Final Report). Retrieved from http://hdl.handle.net/10536/DRO/DU:30080802

McLean Davies, L., Anderson, M., Deans, J., Dinham, S., Griffin, P., Kameniar, B., ... Tyler, D. (2013). Masterly preparation: Embedding clinical practice in a graduate pre-service teacher education programme. Journal of Education and Teaching, 39(1), 93-106. https://doi.org/10.1080/02607476.2012.733193

McMahon, M., Forde, C., \& Dickson, B. (2015). Reshaping teacher education through the professional continuum. Educational Review, 67(2), 158-178. https://doi:10.1080/00131911.2013.846298

Mutton, T., Burn, K., \& Menter, I. (2017). Deconstructing the Carter Review: Competing conceptions of quality in England's 'school-led' system of initial teacher education. Journal of Education Policy, 32(1), 14-33. https://doi.org/10.1080/02680939.2016.1214751

Rubin, A., \& Babbie, E. (2010). Essential research methods for social work (2nd ed.). Belmont, CA: Brooks/Cole and Cengage Learning.

Talbot, D., Denny, J., \& Henderson, S. (2018). 'Trying to decide ... what sort of teacher I wanted to be': Mentoring as a dialogic practice. Teaching Education, 29(1), 47-60. https://doi.org/10.1080/10476210.2017.1347919

Teacher Education Ministerial Advisory Group (TEMAG). (2014). Action now: Classroom ready teachers. Retrieved from https://docs.education.gov.au/system/files/doc/other/action_now_classroom_ready_te achers_print.pdf

Travers, M. (2006). Qualitative interviewing methods. In M. Walter (Ed.), Social research methods: An Australian perspective (pp. 83-112). Melbourne: Oxford University Press. 
Walsh, M. E., \& Backe, S. (2013). School-university partnerships: Reflections and opportunities. Peabody Journal of Education, 88(5), 594-607. https://doi.org/10.1080/0161956X.2013.835158

Woodbury, J. (2017). Stakeholder views of teacher training routes. Teacher Education Advancement Network Journal, 9(1), 80-89. Retrieved from http://eprints.uwe.ac.uk/30934

Yeigh, T., \& Lynch, D. (2017). Reforming initial teacher education: A call for innovation. Australian Journal of Teacher Education, 42(12), 112-127. https://doi.org/10.14221/ajte.2017v42n12.7

Young, K. (2018). CO-CREATE: Teachers' voices to inform special education teacher education. Issues in educational research, 28(1), 220-236. 